\title{
Evaluation of China's Health Resources Allocation Performance
}

\author{
Yunying Yan ${ }^{1, \dagger}$, Xue Lei ${ }^{1, \dagger}$, Huawei Tan ${ }^{2}$, Ling Yu ${ }^{3}$, Peilin Zhang ${ }^{2}$, Fei Chen ${ }^{1, *}$ \\ ${ }^{1}$ School of Public Health and Management, Research Center for Medicine and Social Development, Collaborative Innovation Center of Social \\ Risks Governance in Health, Chongqing Medical University, Chongqing, China \\ ${ }^{2}$ Research Center for Hospital Cost Management of Chongqing, The Ninth People's Hospital of Chongqing, Chongqing, China \\ ${ }^{3}$ College of Foreign Languages, Chongqing Medical University, Chongqing, China
}

\section{Email address:}

tyyoha@163.com (Yunying Yan), cqmu1074leixue@163.com (Xue Lei),1039725514@qq.com (Huawei Tan), hainan08@yahoo.com (Ling Yu),2405818486@qq.com (Peilin Zhang), chenfei6639@126.com (Fei Chen)

${ }^{*}$ Corresponding author

$\uparrow$ Yunying Yan and Xue Lei are co-first authors.

\section{To cite this article:}

Yunying Yan, Xue Lei, Huawei Tan, Ling Yu, Peilin Zhang, Fei Chen. Evaluation of China's Health Resources Allocation Performance. Science Journal of Public Health. Vol. 7, No. 3, 2019, pp. 83-90. doi: 10.11648/j.sjph.20190703.13

Received: May 6, 2019; Accepted: June 5, 2019; Published: June 24, 2019

\begin{abstract}
Background As one of the limited public resources, health resources is the material basis for maintaining health, and its allocation has a direct impact on the demand and utilization of health services, thus affecting the health status of the population How to improve the performance of health resources allocation, to obtain the best social and economic benefits within the least input has become the hot spot of social concern in China. Therefore, the study aimed to evaluate the performance of China's health resources allocation from 2004 to 2015 under the constraint of medical expenses. Methods An input-output performance evaluation index system was constructed under the background of constraint of medical expenses China. This study used the SBM-undesirable model to measure the performance of health resources allocation in 31 provinces of China from 2004 to 2015. Results The performance of health resources allocation measured by the SBM-undesirable model at the national and regional levels was significantly lower than that of the traditional CCR model. The undesirable output redundancy rate and desirable output shortage rate at the national and regional levels were far greater than the health resource input redundancy rate. The reasons for the loss of performance of allocation of health resources in different provinces were different. Conclusions Traditional DEA model overestimated the performance of China's health resource allocation and was less sensitive to its changing characteristics. Undesirable output redundancy and desirable output shortage were the main reasons for the performance loss.
\end{abstract}

Keywords: Health Resources, Allocation Performance, SBM-Undesirable Model, Health Equity, China

\section{Introduction}

The performance of health resources allocation refers to the effectiveness of health resources allocation based on the desirable goals, including the efficiency and quality of health resources allocation. Equity of health resources allocation is an important prerequisite for health equity. Especially in developing countries like China with limited health resources, the fair allocation of health resources is more important for promoting social equity and sustainable development. Improving the performance of health resources allocation has always been the core goal of China's regional health planning. Scientific and effective measurement of the performance level of health resources allocation becomes the evidence-based premise of the path of improving the performance of health resources allocation. Health market features the coexistence of multiple inputs and multiple outputs, the desirable outputs and the undesirable outputs. Therefore, only by constructing a relatively complete and systematic input-output performance evaluation index system and adopting appropriate evaluation methods and models can the performance level be measured scientifically and effectively.

Data Envelopment Analysis (DEA), which was first proposed by Cooper in 1978, is a systematic analysis method for measuring the relative efficiency between input and output of multiple factors [1]. It has been applied in many fields, and 
has gradually formed a number of different characteristics of the efficiency analysis model and method, which is particularly suitable for the efficiency evaluation of complex systems and departments with the character of multiple input-output [2]. At present, traditional DEA models such as CCR model based on constant return to scale, BCC model based on variable return to scale and Malmquist index method based on time series are used by scholars around the world to measure the performance of health resources allocation [3-10]. However, when there is input redundancy or output deficiency (there is non-zero relaxation of input or output), traditional DEA models may make the evaluation efficiency overestimated, resulting in the efficiency distortion [11-12]. Traditional DEA models are radial and angular measurements, which also fails to consider the problem of undesirable output efficiency evaluation when there exists negative externality. It deviates from the characteristics of the coexistence of desirable output and undesirable output in health market, such as irrational growth of medical expenses, excessive medical treatment, hospital infection and other undesirable outputs, resulting in poor quality of health resources allocation. To overcome the insensitivity of the traditional DEA model to the slack in inputs and outputs, Tone constructed the Slacks-Based Measure (SBM) model [13]. Compared to the DEA models, the Slack-Based measurement model has better discriminating power by utilizing slack variables. And undesirable outputs can be incorporated by SBM model without transformation [14]. In addition, the academic community did not raise the concept of health resources allocation efficiency to the scope of health care resource allocation performance. It only stayed at the efficiency analysis level of input-output, which restricted the deepening of theoretical research in the field of health resources allocation performance.

The objective of the study is to construct three heterogeneous performance evaluation index systems including input, desirable output and undesirable output, and to use SBM-undesirable model to measure the efficiency of China's health resources allocation and find the cause of performance loss. This will help to improve the theoretical framework of health resources allocation performance researches and provide accurate evidence for improving the performance of China's health resources allocation.

\section{Materials and Methods}

\subsection{Research Method}

To solve the problem of undesirable output efficiency evaluation in the presence of negative externalities, Tone constructed the SBM-undesirable model in 2007 [15]. This study used the SBM-undesirable model proposed by Tone to measure the efficiency of China's health resources allocation. The model is as follows:

$$
\begin{aligned}
& \rho^{*}=\frac{1-\frac{1}{m} \sum_{i=1}^{m} \frac{s_{i}^{-}}{x_{\mathrm{ik}}}}{1+\frac{1}{\mathrm{n}_{1}+n_{2}}\left(\sum_{r=1}^{n} \frac{\mathrm{s}_{r}^{+}}{y_{r \mathrm{k}}}+\sum_{t=1}^{n_{2}^{2}} \frac{\mathrm{s}_{t}^{\mathrm{b}-}}{b_{r \mathrm{k}}}\right)} \\
& \text { s.t. }\left\{\begin{array}{l}
X \lambda+S^{-}=x_{k} \\
Y \lambda-S^{+}=\mathrm{y}_{k} \\
B \lambda+S^{b}=b_{k} \\
\lambda \geq 0, S^{-} \geq 0, S^{+} \geq 0, S^{-} \geq 0
\end{array}\right.
\end{aligned}
$$

In the formula (1), $\rho^{*}$ refers to the efficiency of health resources allocation, $x_{k}, y_{k}, b_{k}$ refer to input, desirable output and undesirable output index respectively. $S_{i}{ }^{-}, S_{r}{ }^{+}, S_{t}{ }^{b-}$ refer to the input slack index, desirable output slack index and undesirable output slack index respectively. $\mathrm{X}$, $\mathrm{Y}$ and $\mathrm{B}$ refer to input matrix, desirable output matrix and undesirable output matrix respectively. $S_{i}{ }^{-}, S_{r}{ }^{+}, S_{t}{ }^{b-}$ refer to input slack matrix, desirable output slack matrix and undesirable output slack matrix respectively. $\lambda$ refers to the density vector, which represents the weight of each input element. The objective function value $\rho^{*}$ is strictly monotonically decreasing with respect to $\boldsymbol{S}_{i}{ }^{-}, \boldsymbol{S}_{r}{ }^{+}, \boldsymbol{S}_{t}{ }^{b-}$, and $0 \leq \rho^{*} \leq 1$.

\subsection{Input-output Performance Evaluation Index System and Data Source}

The unreasonable increase of medical expenses is the unanticipated medical and health output of the government and residents. Based on this logic, combined with relevant literature and public statistical data, this study constructed an index system of input-output performance of health resources allocation under the constraint of medical expenses control, which included three heterogeneous primary indicators and seven secondary indicators. The paper collected the related panel data of input-output from 2004 to 2015 in 31 provinces (including autonomous regions and municipalities directly under the central government) of China. Health resources input, desirable output and undesirable output data were all from China Health Statistics Yearbook (2005-2013) and China Health and Family Planning Yearbook (2014-2016). To 
eliminate the impact of inflation, the study used the consumer price index of each province $(2004=100)$ to convert the total expenditure of medical institutions, average medical expenses of outpatients and average medical expenses of discharged patients into actual values (Table 1).

Table 1. Performance evaluation index system of health resources allocation.

\begin{tabular}{|c|c|}
\hline Primary Index & Secondary Index \\
\hline \multirow{3}{*}{ Input index } & Numbers of medical technicians \\
\hline & Numbers of beds in medical institutions \\
\hline & Total expenditure of medical institutions \\
\hline \multirow{2}{*}{ Desirable output index } & Numbers of diagnosis and treatment \\
\hline & Number of inpatients \\
\hline \multirow{2}{*}{$\begin{array}{l}\text { Undesirable output } \\
\text { index }\end{array}$} & Medical expenses of hospital outpatients \\
\hline & Medical expenses of hospital discharged patients \\
\hline
\end{tabular}

\subsection{Ethics Statement}

The data from the Statistical Yearbook are publicly available. Informed consent was not needed, as these were secondary data without any personal information.

\subsection{Analysis of the Reasons of Loss of Health Resource Allocation Performance}

In this study, the reasons for the performance loss of health resources allocation were characterized by the redundancy rate of input, the deficiency rate of desirable output and the redundancy rate of undesirable output. The slack of the variable divided by the corresponding input was the redundancy rate of input, the desirable output deficit was the slack of desirable output variable divided by the corresponding output. The redundancy rate of undesirable output was the slack of undesirable output divided by the corresponding undesirable output.

\subsection{Data Analysis}

The study used Office 2010 software to build the database and organized the data, Max DEA 5.2 software to measure the performance of health resources allocation. SPSS 21.0 software was used to carry out independent sample t test on the efficiency measured by CCR model and SBM-undesirable model, and statistical significance was considered at $\mathrm{P}<0.05$.

\section{Results}

\subsection{Efficiency of Regional Health Resources Allocation}

At the national level, the average efficiency of health resources allocation measured by CCR model and SBM-undesirable model from 2004 to 2015 was 0.927 and 0.836 respectively, and the difference was statistically significant $(\mathrm{P}<0.05)$. At the regional level, the health efficiency was higher in the eastern China than other areas. The average efficiency of health resources allocation in eastern China measured by CCR model and SBM-undesirable model from 2004 to 2015 was 0.950 and 0.876 respectively. In the western region, the mean values were 0.932 and 0.837 respectively. the average efficiency in the mid region was lowest, with mean values of 0.889 and 0.780 respectively (Table 2). The differences in the east, central and west regions were statistically significant $(\mathrm{P}<0.05)$.

Table 2. The input and output performance of China's regional health resources allocation from 2004 to 2015.

\begin{tabular}{|c|c|c|c|c|c|c|c|c|}
\hline \multirow{2}{*}{ Year } & \multicolumn{2}{|l|}{ China } & \multicolumn{2}{|c|}{ Eastern region of China } & \multicolumn{2}{|c|}{ Central region of China } & \multicolumn{2}{|c|}{ Western region of China } \\
\hline & CCR & SBM & CCR & SBM & CCR & SBM & CCR & SBM \\
\hline 2004 & 0.915 & 0.819 & 0.939 & 0.838 & 0.854 & 0.758 & 0.933 & 0.843 \\
\hline 2005 & 0.929 & 0.817 & 0.936 & 0.837 & 0.888 & 0.759 & 0.950 & 0.836 \\
\hline 2006 & 0.926 & 0.822 & 0.931 & 0.859 & 0.904 & 0.765 & 0.936 & 0.826 \\
\hline 2007 & 0.887 & 0.762 & 0.918 & 0.811 & 0.860 & 0.691 & 0.877 & 0.764 \\
\hline 2008 & 0.921 & 0.813 & 0.941 & 0.837 & 0.881 & 0.758 & 0.931 & 0.827 \\
\hline 2009 & 0.927 & 0.842 & 0.947 & 0.846 & 0.886 & 0.786 & 0.936 & 0.875 \\
\hline 2011 & 0.934 & 0.846 & 0.974 & 0.942 & 0.897 & 0.787 & 0.923 & 0.797 \\
\hline 2012 & 0.935 & 0.843 & 0.971 & 0.931 & 0.894 & 0.781 & 0.929 & 0.804 \\
\hline 2013 & 0.913 & 0.850 & 0.940 & 0.903 & 0.872 & 0.813 & 0.916 & 0.826 \\
\hline 2014 & 0.948 & 0.881 & 0.974 & 0.918 & 0.908 & 0.833 & 0.951 & 0.879 \\
\hline 2015 & 0.952 & 0.885 & 0.970 & 0.905 & 0.922 & 0.842 & 0.955 & 0.896 \\
\hline mean value & 0.927 & 0.836 & 0.950 & 0.876 & 0.889 & 0.780 & 0.932 & 0.837 \\
\hline average growth rate & $0.36 \%$ & $0.71 \%$ & $0.30 \%$ & $0.70 \%$ & $0.70 \%$ & $0.96 \%$ & $0.21 \%$ & $0.56 \%$ \\
\hline
\end{tabular}

\subsection{Characteristics of Regional Health Resources Allocation Efficiency}

In terms of the rate of change in the efficiency of health resources allocation in China, it showed an upward trend. The average growth rate measured by $\mathrm{CCR}$ model and SBM-undesirable model was $0.36 \%$ and $0.71 \%$ respectively. At the regional level, the eastern, central and western regions all showed a trend of fluctuated increasing, and the growth rate of the central region was the highest and the average growth rate measured by CCR model and SBM-undesirable model was $0.70 \%$ and $0.96 \%$ respectively. The growth rate of the eastern region was $0.30 \%$ and $0.70 \%$ respectively. The growth rate of the western region was $0.21 \%$ and $0.56 \%$ respectively (Figure 1). In terms of the difference of health resources allocation efficiency, the average growth rate of health resources allocation efficiency at the national and regional level measured by $\mathrm{CCR}$ model was lower than 
SBM-undesirable model. The amplitude of wave curve measured by CCR model was lower than that by

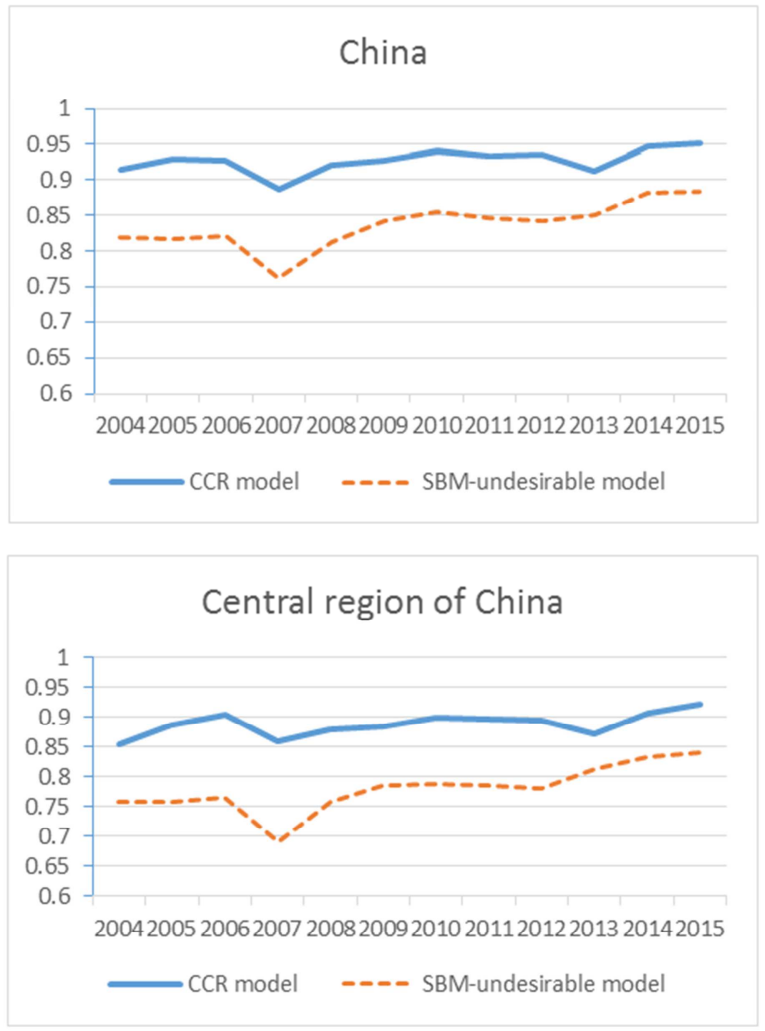

SBM-undesirable model and the fluctuation cycle was higher than that by SBM-undesirable model.

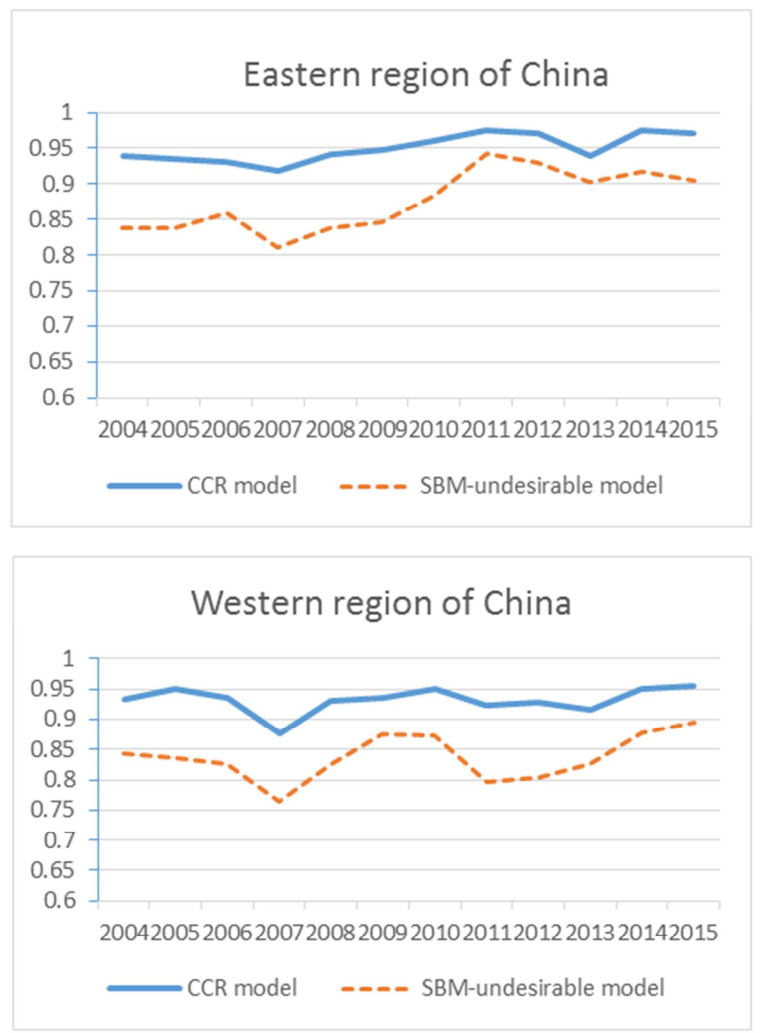

Figure 1. The trend of health resources allocation efficiency of China from 2004 to 2015.

\subsection{Efficiency of Inter-provincial Health Resource Allocation}

Since CCR model did overestimate the efficiency of health resources allocation, this study focused on the inter-provincial health resources allocation efficiency measured by SBM-undesirable model. From 2004 to 2015, the average efficiency of health resources allocation in Guangdong, Henan and Yunnan provinces was $1.000(9.68 \%)$, and the average efficiency was above the national average (35.48\%) in 11 provinces of Shandong, Xinjiang, Fujian, Hebei, Sichuan, Zhejiang, Shanghai, Guangxi, Guizhou, Ningxia and Jiangsu. In addition, the average distribution efficiency in 17 provinces including Anhui, Beijing, Hubei, Hunan, Tibet, Tianjin, Jiangxi, Shaanxi, Gansu, Liaoning, Qinghai, Chongqing, Heilongjiang, Jilin, Inner Mongolia, Shanxi and Hainan were below the the national average level (accounting for 54.84\%). Within the eastern region, 7 provinces were above the national average $(63.64 \%), 4$ provinces were below the national average $(36.36 \%)$. In the central region, one province was above the national average $(12.50 \%), 7$ provinces were below the national average $(87.50 \%)$. In the western region 6 provinces were above the national average $(50 \%)$, while another 6 provinces were below the national average $(50 \%$, Figure 2).

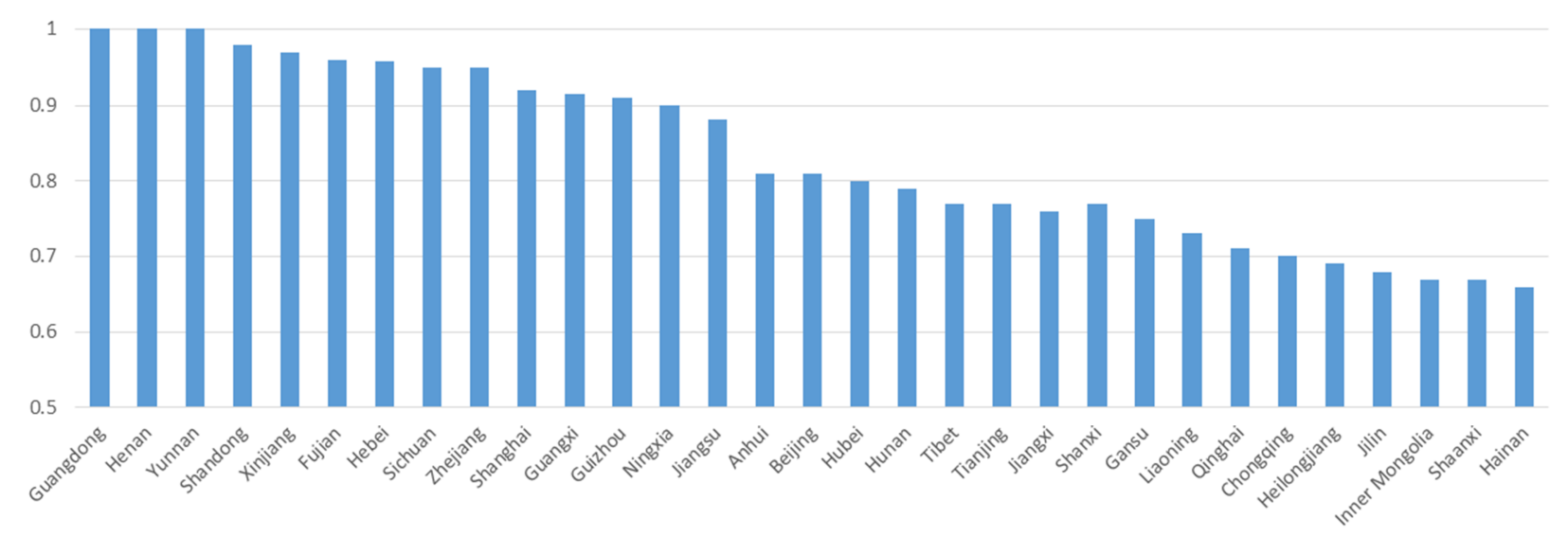

Figure 2. Average efficiency of health resources allocation in 31 provinces of China from 2004 to 2015. 


\subsection{Reasons for Performance Loss of Health Resources Allocation}

The output redundancy of the average outpatients' medical expenses, the redundancy of average medical expenses of discharged patients and the insufficient number of hospital treatment, these were the top three reasons for the performance loss of China's health resources allocation. At national level, their mean rates were $37.14 \%, 34.19 \%$ and $-12.88 \%$. respectively. At the regional level, the mean redundancy rates of out-patients' medical expenses among outpatients in eastern, central and western areas were $30.58 \%$, $46.53 \%$ and $38.18 \%$ respectively. The average redundancy rates of output of medical expenses among discharged patients were $28.82 \%, 39.85 \%$ and $38.16 \%$ respectively. And the deficiency rates of the number of patients in the hospital were $-7.33 \%,-28.66 \%$ and $-10.68 \%$ respectively.

At the national and regional level, the undesirable output redundancy rate was that the outpatient medical expenses was more than that of the discharged patients. The deficiency rate of desirable output was that the number of people who received hospital treatment was larger than that of in-hospital admission. In terms of input redundancy rate, the situation at the national and regional levels was different. At the national level, the redundancy rate of the total expenditure of the medical institutions was higher than the redundancy rate of the input of the number of medical technicians and the bed of medical institutions. And at the regional level, the eastern region had higher redundancy rate of total expenditure of medical institutions than that of medical technicians. In the central region, the input redundancy rate of medical technicians was higher than that of total expenditure of medical institutions. In the western region, the redundancy rate of the bed number of medical institutions was higher than that of the total expenditure of medical institutions.

Besides the three major reasons mentioned above, the reasons for the performance loss of health resources allocation in various provinces are different. For example, the main reasons for the performance loss of Beijing were the insufficiency of desirable output number of hospital admission and the redundancy of total expenditure of medical institutions. For Shanghai, the input redundancy of medical technicians and the insufficiency of desirable output number of hospital admission. Redundancy in the number of beds in medical institutions was also the main reason for performance loss in Chongqing and Sichuan (Table 3).

Table 3. Reasons for the performance loss of health resources allocation in various provinces.

\begin{tabular}{|c|c|c|c|c|c|c|c|}
\hline \multirow[b]{2}{*}{ Province } & \multicolumn{3}{|c|}{ input redundancy rate $(\%)$} & \multicolumn{2}{|c|}{$\begin{array}{l}\text { desirable output insufficiency } \\
\text { rate }(\%)\end{array}$} & \multicolumn{2}{|c|}{$\begin{array}{l}\text { undesirable output redundancy } \\
\text { rate }(\%)\end{array}$} \\
\hline & $\begin{array}{l}\text { the number } \\
\text { of medical } \\
\text { technicians }\end{array}$ & $\begin{array}{l}\text { the number } \\
\text { of hospital } \\
\text { bed }\end{array}$ & $\begin{array}{l}\text { total expenditure } \\
\text { of medical } \\
\text { institutions }\end{array}$ & $\begin{array}{l}\text { the number } \\
\text { of hospital } \\
\text { treatment }\end{array}$ & $\begin{array}{l}\text { the number of } \\
\text { hospital } \\
\text { admissions }\end{array}$ & $\begin{array}{l}\text { outpatient } \\
\text { medical expenses }\end{array}$ & $\begin{array}{l}\text { discharged } \\
\text { patient medical } \\
\text { expenses }\end{array}$ \\
\hline Eastern region & -1.17 & -2.84 & -4.65 & 7.33 & 2.25 & -30.58 & -28.82 \\
\hline Beijing & -6.80 & 0.00 & -20.65 & 5.27 & 17.99 & -43.47 & -42.41 \\
\hline Tianjing & -0.81 & -2.31 & -5.85 & 14.73 & 16.20 & -50.85 & -50.10 \\
\hline Hebei & -0.63 & -0.27 & 0.00 & 5.17 & 0.00 & -9.61 & -6.30 \\
\hline Liaoning & -6.29 & -2.16 & -1.13 & 55.31 & 33.46 & -65.47 & -57.57 \\
\hline Shanghai & -9.70 & -0.02 & 0.00 & 33.80 & 22.17 & -75.44 & -72.80 \\
\hline Jiangsu & -0.12 & -9.45 & 0.00 & 32.31 & 6.53 & -57.15 & -49.32 \\
\hline Zhejiang & -2.07 & -1.70 & 0.00 & 32.98 & 14.00 & -70.96 & -68.56 \\
\hline Fujian & -0.16 & -5.43 & 0.00 & 51.32 & 10.89 & -66.10 & -58.20 \\
\hline Shandong & 0.00 & -4.53 & -9.82 & 0.81 & 2.19 & -19.56 & -18.25 \\
\hline Hainan & -0.08 & -0.13 & -3.90 & 3.81 & 0.20 & -12.02 & -11.26 \\
\hline Central region & -2.13 & -1.76 & -0.39 & 28.66 & 5.10 & -46.53 & -39.85 \\
\hline Shanxi & 0.00 & -2.57 & 0.00 & 26.56 & 0.73 & -36.70 & -31.41 \\
\hline Jilin & -0.51 & -0.13 & -0.23 & 0.15 & 0.00 & -9.63 & -9.41 \\
\hline Heilongjiang & -3.72 & -1.67 & 0.00 & 22.71 & 0.07 & -47.24 & -40.85 \\
\hline Anhui & -1.95 & -1.27 & -0.66 & 1.00 & 0.00 & -0.64 & -0.39 \\
\hline Jiangxi & -5.51 & -0.67 & -1.31 & 28.24 & 1.55 & -37.85 & -28.96 \\
\hline Henan & 0.00 & 0.00 & 0.00 & 0.00 & 0.00 & 0.00 & 0.00 \\
\hline Hubei & -0.91 & -1.77 & 0.00 & 52.27 & 2.03 & -34.29 & -20.26 \\
\hline Hunan & 0.00 & -8.27 & -3.55 & 25.46 & 1.41 & -21.05 & -17.88 \\
\hline Western region & -2.59 & -3.29 & -0.45 & 10.68 & 2.51 & -38.18 & -38.16 \\
\hline Inner Mongolia & -2.99 & 0.00 & -0.54 & 2.91 & 0.00 & -20.73 & -20.66 \\
\hline Guangxi & -14.18 & 0.00 & 0.00 & 28.50 & 11.16 & -92.15 & -91.82 \\
\hline Chongqing & 0.00 & -14.34 & -2.50 & 32.24 & 0.47 & -73.00 & -66.55 \\
\hline Yunnan & 0.00 & 0.00 & 0.00 & 0.00 & 0.00 & 0.00 & 0.00 \\
\hline
\end{tabular}




\begin{tabular}{llllllll}
\hline & \multicolumn{2}{l}{ input redundancy rate (\%) } & & \multicolumn{2}{l}{$\begin{array}{l}\text { desirable output insufficiency } \\
\text { rate (\%) }\end{array}$} & \multicolumn{2}{l}{$\begin{array}{l}\text { undesirable output redundancy } \\
\text { rate (\%) }\end{array}$} \\
\cline { 2 - 8 } Province & $\begin{array}{l}\text { the number } \\
\text { of medical } \\
\text { technicians }\end{array}$ & $\begin{array}{l}\text { the number } \\
\text { of hospital } \\
\text { bed }\end{array}$ & $\begin{array}{l}\text { total expenditure } \\
\text { of medical } \\
\text { institutions }\end{array}$ & $\begin{array}{l}\text { the number } \\
\text { of hospital } \\
\text { treatment }\end{array}$ & $\begin{array}{l}\text { the number of } \\
\text { hospital } \\
\text { admissions }\end{array}$ & $\begin{array}{l}\text { outpatient } \\
\text { medical expenses }\end{array}$ & $\begin{array}{l}\text { discharged } \\
\text { patient medical } \\
\text { expenses }\end{array}$ \\
\hline Tibet & -2.81 & -4.47 & -3.07 & 15.49 & 34.70 & -45.31 & -46.59 \\
Shaanxi & -8.44 & -1.81 & 0.00 & 13.52 & 2.19 & -51.86 & -45.88 \\
Gansu & -3.18 & -7.50 & 0.00 & 15.45 & 10.02 & -58.06 & -58.43 \\
Qinghai & -1.83 & -1.89 & -0.30 & 23.15 & 6.48 & -74.87 & -76.52 \\
Ningxia & -0.31 & 0.00 & 0.00 & 0.99 & 1.71 & -28.05 & -27.73 \\
Xinjiang & 0.00 & -0.01 & 0.00 & 1.54 & 0.00 & -5.62 & -5.12 \\
China & -1.83 & -2.62 & -2.84 & 12.88 & 3.19 & -37.14 & -34.19 \\
\hline
\end{tabular}

\section{Discussions}

The study showed that performance of health resources allocation at the national and regional levels measured by SBM-undesirable model was significantly lower than that of the traditional CCR model, which meant that traditional DEA model did overestimate the performance of China's health resources allocation. The amplitude of wave curve measured by the traditional CCR model was lower than that by SBM-undesirable model and the fluctuation cycle was higher than that by SBM-undesirable model, which meant that the traditional DEA model was less sensitive to the changing characteristics of China's health resources allocation performance. Results above suggested that SBM-undesirable model did fit the characteristics of multi-input and multi-output, desirable output and undesirable output of the health system and had strong applicability and advancement in the field of health performance evaluation.

The study showed that the performance of China's health resources allocation was fairly high (The mean values measured by CCR model and SBM-undesirable model was 0.927 and 0.836 respectively), which was consistent with existing researches in China $[8,10,16]$. However, the regional differences were obvious, and the central region of China suffered the worst efficiency of health resources allocation. The reasons for poor performance of the central region might be related to the undeveloped economy, weak financial self-sufficiency, the tension between the supply and demand of health care resources owing to the large population within this area and the unbalanced national health policies that featured transfer payments [17, 18]. But the problem was looking up since the efficiency of central region was improving at a faster rate than either eastern or western regions.

The research showed that the average growth rate of the efficiency of health resources allocation at national and regional levels was positive from 2004 to 2015, indicating that the performance of health resources allocation in China was improving. The conclusion was consistent with recent researches $[10,16]$. However, the growth curve of efficiency of China's health resources allocation was characterized by a large fluctuation range and short volatility period which showed that the efficiency improvement trend of China's health resources allocation has no pattern to follow. It happened for multiple reasons: the poor productivity and stability of the health system, the non-quantitative standard of government financial investment, the lack of linkage between the micro-performance of medical institutions and the macro-performance of the health system and the changing of China's health policies against a larger mandatory policy background [19-21].

The research showed that the efficiency loss rates of health resources allocation in China were as follows (from high to low): the rate of undesirable output redundancy, the desirable output deficit, the input redundancy rate. And the desirable output redundancy rate was much higher than the other two. It was to be noted that this study had a different finding from other studies that the input redundancy rate of China's health resources was extremely low, which meant the waste of China's health resources was not conspicuous $[8,10,16]$. This conclusion was in line with the fact that China was still at the initial stage of health.

Compared with developed countries the ratio of doctor/nurse and nurse/ bed in China was still quite low [10]. And China's health resources investment was for the increase of total factor productivity. In addition, the contradiction between supply and demand of medical services in China was still serious. Under the quasi-market mechanism of 'self-financing', the self-motivation and restraint mechanism of medical institutions was more sensitive to the input of health resources [20]. It was suggested that the regional health planning policies in China should give priority to the output rather than the input of health resources. The policy measures should give priority to solving the problems of the undesirable output redundancy and the insufficient desirable output for better marginal benefit.

As mentioned above, among the eastern, central and western regions, the redundancy rate of undesirable output was much higher than the deficit rate of desirable output and the redundancy rate of input, which showed that the reasons for the loss of efficiency of health resources allocation of inter-regional were similar. In different provinces within a central region, the reasons for the performance loss of health resources allocation were different: in the eastern region, there were five major factors for Shanghai, and four major factors for Beijing, Tianjin, Liaoning, Shandong and Fujian. In the central region, there were five major factors for Guangxi, and four for Chongqing, Sichuan, Tibet, Gansu and Qinghai. 


\section{Conclusions}

The health care resource allocation performance measured by SBM-undesirable model at the national and regional levels were significantly lower than by the traditional CCR model, which meant that traditional DEA model overestimated the performance of China's health resources allocation and was less sensitive to its changing characteristics. SBM-undesirable model had strong applicability and advancement in the field of health performance evaluation. The performance of China's health resources allocation was fairly high, while the differences between regions and provinces were significant. The performance of inter-regional health care resource allocation in the eastern region was the highest, followed by the western region and the central region. The average growth rate of health care resource allocation performance at the national and regional levels from 2004 to 2015 was positive. The efficiency of China's health resources allocation was improving, but the trend was irregular. Undesirable output redundancy and the lack of desirable output were the main reasons for the performance loss of China's health resources allocation. The reasons for the performance loss of health resources allocation among various regions were similar, while the causes in various provinces were different. According to the existing situation, it is important to establish the mechanism of evaluation, supervision and feedback of health resources allocation performance, to give priority to the undesirable output redundancy and lack of desirable output and focus on regional performance loss convergence and heterogeneity.

\section{Competing Interests}

The authors declare that they have no competing interests.

\section{Acknowledgements}

This work was funded by Chongqing Yuzhong Science and Technology Commission under grant No. 20170146, Chongqing Social Science Federation under grant No. 2017ZDYY42 and Chongqing Municipal Education Commission under grant No.18SKGH019. We would also be grateful to many other people had helped and made remarkable contributions during the investigation.

\section{References}

[1] Charnes, A., Cooper, W. W., Rhodes, E.. Measuring the efficiency of decision making units. European Journal of Operational Research, 1978, 2 (6), 429- 444.

[2] Cooper W W, Tone K, Seiford L M. Data Envelopment Analysis: A Comprehensive Text with Models, Applications References, and DEA-Solver Software with Cdrom. Kluwer Academic Publishers, 1999.

[3] Hollingsworth B. Non-parametric and parametric applications measuring efficiency in healthcare. Health Care Management Science, 2003, 6: 203-218.
[4] Worthington A C. Frontier efficiency measurement in health care: a review of empirical techniques and selected applications. Medical Care Research \& Review, 2004, 61: 135-170.

[5] Hussey P S, Han D V, Romley J, et al. A Systematic Review of Health Care Efficiency Measures. Health Services Research, 2010, 44: 784-805.

[6] Campos M S, Fernández-Montes A, Gavilan J M, et al. Public resource usage in health systems: a data envelopment analysis of the efficiency of health systems of autonomous communities in Spain [J]. Public Health, 2016, 138: 33-40.

[7] Pang, H. M., Wang, X. W., 2010. Study on the interphase efficiency of large comprehensive hospitals in China based on the Malmquist index of DEA. Chinese Hospital Management. 30, 35-37. (in Chinese).

[8] Xie, J. L., Fang, P. Q., 2015. Research on the fairness and efficiency of the allocation of medical and health resources among provinces in China. Chinese Health Economics. 32, 60-62. (in Chinese).

[9] Wang, X. W., Cui, Y. Y., Feng, R. H., 2015. Study on the efficiency characteristics and changes of county hospitals. Chinese Journal of Health Policy. 8, 13-20. (in Chinese).

[10] Zhao, L., Zhang, H., Wang, Y. G., 2015. Evaluation of China's provincial health resources allocation efficiency based on Malmquist index of DEA. Chinese Journal of Health Statistics. 32, 984-987. (in Chinese).

[11] Liu, X, Li, S. M., 2015. Empirical analysis of energy efficiency of provinces in China based on undesirable output SMB model. Mathematics in Practice and Theory. 45, 35-43. (in Chinese).

[12] Hu, B., Wang, F., Li, J. Y., 2015. Empirical Study on efficiency evaluation of urban ecological civilization construction based on undesirable output SBM model. Journal of arid land resources and environment. 29, 13-18. (in Chinese).

[13] Tone K. A slacks-based measure of efficiency in data envelopment analysis. European Journal of Operational Research, 2001, 130: 498-509.

[14] Guo Y, Li N, Mu H, et al. Regional Total-Factor Coal Consumption Efficiency in China: A Meta-Frontier SBM-Undesirable Approach. Energy Procedia, 2017, 142: 2423-2428.

[15] Cooper, W. W., Seiford, L. M., Tone, K., 2007. DATA ENVELOPMENT ANALYSIS A Comprehensive Text with Models, Applications, References Second Edition. Boston: Kluwer Academic Publishers.

[16] Zhang, H., Zhao, L., Liu, Q., 2016. Research on the allocation efficiency of health resources in China based on the combination analysis of DEA and SFA. Chinese Journal of Public Health. 32, 1195-1197. (in Chinese).

[17] Xu, M. M., Liu, J. T., 2016. Study on the Equity of Public Health Expenditure in Beijing, Henan and Shaanxi. Chinese Health Economics. 35, 45-48. (in Chinese).

[18] Tan, H. W., Zhang, P. L., Liu, X., 2017. The mechanism and empirical analysis of the impact of central transfer payment on health expenditure of local governments. Chinese Health Economics. 36, 16-20. (in Chinese). 
[19] Tan, H. W., Zheng, W. H., Zhang, Y., 2016. Analysis of operational efficiency of three level public hospitals in Chongqing from the perspective of heterogeneity of production technology. Journal of Shanghai Jiaotong University (Medical Science)., 36, 1063-1069. (in Chinese).

[20] Tan, H. W., Zheng, W. H., Zhang, Y., 2016. Study on the cost efficiency and its influencing factors of County-level public hospitals in chongqing. Journal of Shanghai Jiaotong
University (Medical Science). 36, 730-736. (in Chinese).

[21] Wang, X. T., 2014. Research on health input, technical efficiency and health performance, based on SFA method to measure health input efficiency. Chinese Health Economics. 33, 25-29. (in Chinese). 